Cahiers $d u$ MONDE RUSSE

\section{Cahiers du monde russe}

Russie - Empire russe - Union soviétique et États indépendants

$51 / 4 \mid 2010$

Sciences humaines et sociales en Russie à l'Âge d'argent

\title{
Victor Dönninghaus, Minderheiten in Bedrängnis
}

\section{Gábor T. Rittersporn}

\section{(2) OpenEdition}

\section{Journals}

Édition électronique

URL : https://journals.openedition.org/monderusse/7441

DOI : 10.4000/monderusse. 7441

ISSN : 1777-5388

Éditeur

Éditions de l'EHESS

\section{Édition imprimée}

Date de publication : 25 novembre 2010

Pagination : 807-810

ISBN : 978-2-7132-2316-7

ISSN : $1252-6576$

Référence électronique

Gábor T. Rittersporn, « Victor Dönninghaus, Minderheiten in Bedrängnis », Cahiers du monde russe [En ligne], 51/4 | 2010, mis en ligne le 09 décembre 2011, consulté le 02 septembre 2022. URL : http:// journals.openedition.org/monderusse/7441; DOI : https://doi.org/10.4000/monderusse.7441

Ce document a été généré automatiquement le 2 septembre 2022

Tous droits réservés 


\title{
Victor Dönninghaus, Minderheiten in Bedrängnis
}

\author{
Gábor T. Rittersporn
}

\section{RÉFÉRENCE}

Victor DöNNINGHAUS, Minderheiten in Bedrängnis. Sowjetische Politik gegenüber Deutschen, Polen und anderen Diaspora-Nationalitäten 1917-1938. Oldenbourg Verlag : Munich, 2009, 693 p. (Schriften des Bundesinsitituts für Kultur und Geschichte der Deutschen im östlichen Europa, vo. 35)

1 En suivant les notes infrapaginales de cette étude sur la politique ethnique en URSS, le lecteur trouve de plus en plus de références à des sources provenant des organes de sécurité lorsqu'il s'approche de la fin des années 1920 et surtout lorsqu'il s'aventure audelà du début de la collectivisation violente de l'agriculture. Il serait sans doute exagéré d'attribuer le nombre croissant de ces documents policiers à une préparation quelconque de la grande purge des années 1937-1938. Des recherches récentes arrivent à la conclusion que le Kremlin aurait déclenché la terreur précipitamment, sans aucune planification ni organisation préalables. Or, les sources utilisées pour cet ouvrage montrent autre chose : il s'agirait d'une pratique administrative où la police secrète aurait joué un rôle toujours plus important.

2 Certes, les minorités qui font l'objet de la monographie de Victor Dönninghaus sont un peu particulières. On peut les qualifier de diasporas ethniques. Allemands, Polonais, Lettons, Estoniens, Finnois et Lituaniens avaient souvent des liens à l'étranger; mais, surtout, ils avaient des compatriotes au-delà des frontières, qui vivaient dans des États nationaux où ils formaient la population majoritaire.

3 Dans un premier temps, la politique de l'État-parti à leur égard fut hésitante. Ces peuples semblaient jeter un pont entre la Russie soviétique et l'Ouest dans l'hypothèse d'une vague révolutionnaire qui se serait emparée du pays de leurs parents ou de leurs aïeux. En revanche, ils risquaient de poser plus de problèmes que d'apporter de solutions en cas 
d'échec de cette révolution. Au début, les autorités penchèrent tantôt vers une stratégie de développement, censée faire la démonstration des avantages du modèle de société bolchevique qu'elles espéraient étendre au moins entre l'océan Pacifique et l'Atlantique, tantôt vers un pragmatisme qui n'accordait pas trop d'importance à des groupes disséminés sur un immense pays.

Pour compliquer les choses, rien n'était plus ardu que de mettre au point une politique valable pour une ethnie entière, $a$ fortiori pour l'ensemble des diasporas. Dönninghaus a en outre choisi un domaine où les difficultés apparaissaient le plus clairement: l'éducation au sens large du terme. Il était en effet particulièrement complexe de gérer un nombre souvent minime de personnes appartenant à l'une de ces minorités dans une multitude de localités.

5 Rien que la définition de la langue maternelle de tel ou tel groupe posait problème. Par exemple, moins de la moitié de ceux qui s'étaient déclarés Polonais lors du recensement de 1926 étaient capables de lire Mickiewicz ou Sienkiewicz dans l'original ; quant à l'autre moitié, elle était quasiment analphabète. Beaucoup de Biélorusses catholiques se désignaient comme Polonais; certains Polonais, en particulier dans les zones frontalières, se désignaient comme Biélorusses ou comme appartenant à d'autres nationalités. Toutes ces données étaient largement floues.

6 Les Allemands étaient plus alphabétisés, maîtrisant presque tous la langue de leurs ancêtres qu'ils n'étaient guère prêts à renier. En grosse majorité, ils étaient agriculteurs, mais leurs villages illustrent un autre problème. En effet, les tsars avaient invité des cultivateurs allemands depuis le xviII ${ }^{e}$ siècle à venir coloniser divers territoires de l'Empire. Les invités avaient répondu à la proposition avec beaucoup d'entrain et de succès, mais sans faire d'efforts pour s'assimiler. Leurs communes étaient repliées sur elles-mêmes et n'appréciaient pas nécessairement les tentatives d'agitprop émanant d'anciens prisonniers de guerre des armées allemande et austro-hongroise qui s'étaient rangés du côté des bolcheviks et venaient répandre la bonne parole parmi la diaspora germanophone. Celle-ci était fort pieuse, puisque des villages entiers étaient constitués de descendants de croyants qui avaient fui des persécutions religieuses. Les habitants d'une localité appartenaient souvent en bloc à une seule congrégation. Il était difficile de trouver dans leurs milieux des enseignants totalement acquis à la cause soviétique. Traditionnellement, dans les villages allemands, les instituteurs cumulaient les fonctions de prédicateur ou de sacristain, vocations qui n'étaient pas forcément compatibles avec les préceptes du matérialisme dialectique et historique.

7 Mutatis mutandis, la situation n'était pas tellement différente avec les autres minorités. Mais il n'y avait pas le choix. Les autorités essayaient de miser sur les plus jeunes qui venaient de finir leurs études et qu'elles croyaient plus acquis au régime, ou encore sur des enseignants importés d'autres parties du pays et qui n'étaient pas nécessairement de la même minorité que celle où ils échouaient. Les résultats sont faciles à imaginer : si le niveau d'éducation de la plupart des ethnies étudiées par Dönninghaus était parmi les plus élevés du pays au milieu des années 1920, il commença à baisser vers la fin de la décennie.

8 L'espoir de la révolution mondiale s'étant évanoui définitivement vers le milieu des années 1920, les diasporas nationales perdirent leur importance aux yeux du régime. Malgré tout, leurs intérêts étaient représentés par des organismes spécifiques dans diverses institutions dirigeantes, y compris au sein du parti. Mais cette faveur ne dura pas longtemps. L'abolition graduelle de ces organismes priva la plupart des ethnies 
d'accès direct aux grands décideurs. À l'exception des endroits où elles étaient fortement représentées dans les administrations locales, comme en Carélie ou dans la République autonome des Allemands de la Volga, elles ne bénéficiaient guère de la politique de l'État-parti consistant à promouvoir des cadres indigènes aux postes de responsabilité.

9 La crise agraire et les fausses alarmes de guerre ne facilitèrent pas la situation de ces minorités que la police secrète croyait étroitement liées à l'étranger, particulièrement les Polonais et les Allemands. L'opposition des paysans allemands à la collectivisation prit une forme originale : des villages entiers décidèrent d'émigrer aux États-Unis et au Canada. Nombre de ces candidats à l'émigration étaient des Mennonites - qui avaient déjà eu pour tradition de quitter collectivement l'Empire russe -, une tradition qu'ils maintinrent jusqu'au milieu des années 1920 puisqu'au début, le nouveau régime ne les empêchait pas de s'expatrier. À l'automne 1920, environ vingt mille cultivateurs allemands étaient rassemblés à Moscou dans l'attente de l'autorisation de quitter le pays. Très peu de familles l'obtinrent, tout juste celles qui eurent la chance d'arriver avant que le mouvement ne s'amplifie. Mais celui-ci se poursuivit en 1930 un peu partout dans des colonies allemandes, de la Crimée jusqu'à la Sibérie et au Kazakhstan. L'appareil du Comité central recevait aussi des informations sur l'intention d'émigrer des Polonais, des Grecs et des Tchèques.

10 Il n'est donc pas surprenant que la police ait étiqueté les Mennonites comme contrerévolutionnaires et ait nourri des soupçons d'agissements antisoviétiques à grande échelle à l'égard de la minorité allemande comme d'autres ethnies. Il n'est pas étonnant non plus que Dönninghaus cite toujours plus de données des organes de sécurité au fur et à mesure que sa narration avance dans les années 1930. Les tensions traditionnelles avec la Pologne et l'avènement du régime nazi en Allemagne intensifiaient la manie des politiciens et des policiers de voir des activités subversives et des ennemis partout, et les nationalités soupçonnées de loyauté douteuse en faisaient les frais: les autorités les éloignaient des zones frontalières, les traitaient de plus en plus de cinquième colonne potentielle, bien avant que le terme ne fasse son chemin de Madrid à Moscou. Les efforts du gouvernement allemand et des associations humanitaires allemandes pour faire parvenir de l'aide à leurs compatriotes pendant la grande famine exposaient ceux qui la distribuaient comme ceux qui la recevaient à l'accusation de sympathies avec les nazis dont les intentions étaient à peine moins propagandistes qu'humanitaires.

11 Néanmoins, l'auteur va un peu vite en besogne en établissant un lien direct avec les massacres aveugles de 1937-1938. On comprend mal, par exemple, pourquoi les autorités ont continué à transférer des familles appartenant aux diasporas ethniques, avec leurs biens, des frontières vers l'intérieur du pays, jusqu'à la veille même de la Terreur, alors que sont restés jusqu'à la guerre des Polonais, des Allemands, des Lettons et des membres d'autres minorités, situés géographiquement près de pays pour le compte desquels ils étaient accusés de mener des activités subversives. Mais Dönninghaus a sans doute raison d'arrêter sa chronique à la fin de la grande purge. L'agression contre la Pologne et les Pays baltes, la déportation de la minorité allemande vers la Sibérie et l'Asie centrale, la guerre, l'incorporation définitive des marches orientales à l'Union soviétique et le nouveau régime de Varsovie constituent le début d'un nouveau chapitre.

En conclusion, voici un livre intéressant qui réunit l'apport d'une documentation jusqu'ici inconnue et la synthèse de travaux récents. Un lecteur pointilleux calculerait que Dönninghaus consacre plus d'attention à la minorité allemande qu'à d'autres ethnies. 
Mais ce même lecteur, qui reste souvent sur sa faim à la lecture d'ouvrages sur les Allemands d'Union soviétique, avouera qu'il a beaucoup appris. 